Bol. Acad. peru. leng. 50. 2010 (11-33)

\title{
EL NARRADOR TRANSDIEGÉTICO Y OTROS \\ PROCEDIMIENTOS DE LA VOZ NARRATIVA EN LOS \\ CACHORROS, DE MARIO VARGAS LLOSA, COMO \\ ELEMENTOS DE UNA REPRESENTACIÓN VEROSÍMIL DE \\ LA REALIDAD SOCIAL
}

LE NARRATEUR TRANSDIÉGÉTIQUE ET D'AUTRES

PROCÉDURES DE LA VOIX NARRATIVE CHEZ LOS

CACHORROS, DE MARIO VARGAS LLOSA, COMME

ÉLÉMENTS D'UNE RÉPRESENTATION VRAISEMBLABLE

DE LA RÉALITÉ SOCIALE

\section{THE TRANSDIEGETIC NARRATOR AND OTHER PROCEDURES OF THE NARRATIVE VOICE IN LOS \\ CACHORROS, BY MARIO VARGAS LLOSA, AS ELEMENTS \\ OF A REALISTIC REPRESENTATION OF SOCIAL REALITY}

\author{
José R. Valles Calatrava \\ Catedrático de Teoría de la Literatura \\ Universidad de Almería
}

\section{Resumen:}

Tras una breve introducción sobre el rol de la realidad, la ficción y la memoria en Los cachorros (1967) de Vargas Llosa, este articulo estudia los cuatro procedimientos de la voz narrativa utilizados para enfatizar lingǘstica y narrativamente la dimensión semántica realista de la obra: una -apa- 
rente - nueva modalidad de narrador que he denominado transdiegético, la polifonía coral junto a la visión caleidoscópica, la yuxtaposición y nivelación de estilos y discursos y la inserción del sociolecto de la juventud limeña burguesa de la época.

\section{Résumé:}

Après une brève introduction sur le rôle de la réalité, la fiction et la mémoire chez Los cachorros (1967) de Vargas Llosa, cet article étudie les quatre procédures de la voix utilisées pour souligner la dimension sémantique réaliste de l'œuvre: une apparente - nouvelle modalité de narrateur que j'ai nommé transdiégétique, la polyphonie chorale et la vision kaléidoscopique, la juxtaposition et le nivellement de styles et des discours et l'insertion du sociolecte de la jeunesse bourgeoise de Lima à cette époque.

\section{Abstract:}

After a short introduction on the role of reality, fiction and memory in Los Cachorros (1967) by Vargas Llosa, this article studies the four procedures of the voice used to emphasize in a linguistic and narrative way the realistic semantic dimension of the work: an - apparent - new type of narrator that I have named as transdiegetic, the choral polyphony together with the kaleidoscopic vision, the juxtaposition and leveling of styles and speeches and the sociolect insertion of the bourgeois youth of that era in Lima.

\section{Palabras clave:}

novela española del siglo XX; novela experimental; crítica literaria; teoría de la literatura; narratología; técnicas narrativas; narrador transdiegético; polifonía; visión caleidoscópica; sociolecto.

\section{Mots clés:}

Roman espagnol du XXe siècle; roman expérimental; critique littéraire; théorie de la littérature; narratologie; techniques narratives; narrateur transdiégétique; polyphonie; vision kaléidoscopique; sociolecte.

Key words:

Twentieth-Century Spanish Novel; Experimental Novel; Literary Criticism; Literary Theory; Narratology; Narrative Techniques; Transdiegetic Narrator; Polyphony; Kaleidoscopic Vision; Sociolect. 
Fecha de recepción:

$30 / 09 / 2010$

Fecha de aceptación:

$17 / 10 / 2010$

\section{Introducción: Los cachorros entre la ficción y la realidad, la invención y la memoria}

Aparte de su amplio conocimiento por parte del público lector, particularmente peruano y español, y de la considerable aportación de la crítica sobre esta novela corta de Vargas Llosa, Los cachorros, editada por vez primera por Tusquets en 1967, hace ya 43 años, ha tenido este 2010 un momento especialmente fructífero en su estudio y difusión.

Precisamente ese sello, en su antigua colección "Palabra e imagen", acaba de sacar en facsímil la edición original, en la que interactuaban transgenérica y dialógicamente el texto de Vargas Llosa con las 35 fotografías de Xavier Miserachs, precedida de un interesante y evocador prólogo de Esther Tusquets. Asimismo, al menos - que yo sepa - dos ediciones críticas juveniles, una peruana y otra española, acaban de reeditar el relato precedido de estudios introductorios. ${ }^{1}$

Unos pocos meses antes, también las tablas limeñas habían acogido la obra, en una excelente adaptación y dirección de Miguel Pastor, a la que pudo asistir en Navidad el propio Vargas Llosa, como ya lo había hecho en 2005 con la versión primera del mismo director, heredera de

1 CASORRÁN, MARÍN, Ma J. Estudio critico de "Los Cachorros", Zaragoza, Mira Editores, 2010. GRACIA FANIO, M ${ }^{\mathrm{a}}$ P. y HERRERO FERNÁNDEZ, M ${ }^{\mathrm{a}}$ T. En torno $a$ Los Cachorros de Mario Vargas Llosa. Estudio crítico, Lima, Aladrada (col. Clarión), 2010. Se trata de una novela con mucha tradición de lectura obligada y recomendada para los jóvenes que cursan estudios secundarios, sobre todo, aunque no exclusivamente, en Perú, también en España por ejemplo; no obstante, tiene incluso versiones y ediciones ad usum delphini, infantiles.

En mi opinión, sin embargo, pese a su protagonismo, ambientación y habla, la obra en sí, desde la perspectiva del uso del lenguaje y las técnicas narrativas y de la tematización de la castración y la frustración individual, así como del fracaso grupal y del desarraigo social, parece bien seria y más dirigida a un público adulto, cultural y lectoralmente formado. 
la adaptación pionera, también vista por el autor y Carmen Balcells, que había realizado en 1970 el reconocido director Alonso Alegría, con la idea eje de la acción de que Pichula Cuéllar quería convertirse sexualmente en un hombre normal, según el propio Alegría (2001: 212). El cine había sido mucho más rápido, y el mexicano Jorge Fons filmó la obra en 1971, tan solo cuatro años después de su edición.

Y es que la historia en sí, el proceso de paulatina perturbación psicológica y desafección social de un joven castrado de la burguesía limeña, es más que sugerente y con unos altos índices transductivos (Valles, 2004: 586) de adaptabilidad a las artes escénicas y visuales; concuerda, además, bastante con la pauta ideotemática más característica de su narrativa: según Ortega (1997: 84), “el degradado infierno romántico de la sociedad como destino, como pérdida de la autenticidad, y como espacio heroico de contestaciones imposibles y frustraciones derogatorias".

La obra cuenta, a lo largo de seis capítulos, la evolución de un grupo de jóvenes escolares del colegio miraflorino Champagnat, desde la llegada de un nuevo alumno, Cuéllar y su castración por un perro, hasta la paulatina separación del grupo por la edad y la muerte en accidente del anterior. Si la localización, de acuerdo a ese principio de trabajar cartográficamente en la novela, de operar con escenarios físicos reconocibles y vividos, según Oviedo (2001: 237), es esencialmente miraflorina en particular y limeña en general, ciertas referencias de cronología interna -Pérez Prado, James Dean, Elvis Presley — sitúan la acción en los años cincuenta (Fernández Ariza, 1998: 20).

Es evidente la dimensión semántica-realista del relato. ${ }^{2}$ Con las posteriores salvedades sobre su capacidad de experimentación lingüística y trascendencia del mimetismo narrativo, su localización de los relatos a partir de espacios vividos y/o conocidos de cerca y su uso de la objetividad del relato y la flaubertiana imparcialidad del narrador, Oviedo (2007: 19-20)

2 Cuanto más reviso los argumentos de Fernández Carmona (2007) sobre el carácter naturalista de la obra de MVLL en general - y sobre todo, muchas otras afirmaciones, ideas y juicios - más me convenzo de su filiación realista. 
explica el carácter a la vez realista y de búsqueda formal que tiene el proyecto novelístico de Vargas Llosa -incluyendo Los cachorros - publicado en la década de los sesenta, desde La ciudad y los perros (1963) hasta Conversación en La Catedral (1969), pasando por La casa verde (1965). Dice así:

Conversación en La Catedral señala, pues, el momento de máxima expansión del esfuerzo de Vargas Llosa por usar el lenguaje novelístico como un universo ficticio que rivaliza en complejidad y riqueza con el mundo real del que emana. Sin duda, el conjunto de estas tres primeras novelas - a las que bien puede sumarse el relato largo o novela corta Los cachorros (1967) - presenta un definido perfil estético que puede llamarse 'realista' (...) (Oviedo, 2007: 19).

Pero el marcado carácter realista de la novela que analizo, un acto de escritura ficcional por ontología, deriva esencialmente no solo de los elementos de la realidad observados por su creador y filtrados al mundo de la ficción en la novela, sino también del ámbito de la evocación y de los recuerdos, de los hechos y momentos vividos por el autor en su juventud y que, aunque modificados y camuflados, distanciados y en ocasiones tamizados por el humor y/o cierto tono sentimental, en varias ocasiones parecen calar e intertextualizarse en el relato. Aunque en Lima, antes de ingresar al colegio militar en 1950, Vargas Llosa fue a La Salle y no visitaba al principio Miraflores sino los fines de semana a casa de sus tíos, en El pez en el agua, ese gran ejercicio memorialístico que desvela alternativamente las dos grandes pasiones literatura y política - de la vida de Vargas Llosa (Armas Marcelo, 2001: 67), como en Los cachorros, aparece: un gran danés de Cochabamba que casi mordió al autor; un hermano Leoncio que quiso hacerle algo peor; la afición al fútbol y a nadar en la piscina; los clubes miraflorinos; los ídolos del deporte como Totó Terry o el Conejo Villarán; los paseos por el parque y las matinales de cine en ese barrio; los cigarrillos Viceroy y las copitas de capitán; los primeros descubrimientos de la atracción por las chicas... (Vargas Llosa, 1993: 11-36 y 58-89); todos ellos datos de la vida juvenil del autor que parecen asomar de algún modo, con mayor o menor claridad y trascendencia, en esta narración. 
No obstante, lo que a mí me interesa, particularmente para este trabajo, no es la historia como tal, ni tampoco deslindar la procedencia real o memorialística, externa o personal, de los mimbres de la novela, sino los mecanismos narrativos usados por la voz narrativa para impulsar su dimensión realista.

\section{Los procedimientos coactuantes en la voz narrativa para la recreación realista de la imagen de un grupo juvenil miraflorino en la década de los años cincuenta}

El propio autor, quien al margen de su brillantez narradora se caracteriza por su agudeza crítica y su gran capacidad de reflexión metanarrativa, es lógicamente muy consciente del más que relevante papel que juega la voz en su relato; lo resume así en unas conocidas palabras:

"El relato está contado por una voz plural, que caprichosamente y sin aviso ondula de un personaje a otro, de una realidad objetiva (un acto) a otra subjetiva (una intuición, un pensamiento), del pasado al presente o al futuro y, por momentos, en vez de contar, canta, 'caprichosamente', es un decir, claro. La idea es que esta voz colectiva, saltarina, serpentina, que marea al lector y (musicalmente) lo maltrata, vaya insensiblemente contaminándolo de la historia de Cuéllar, empapándolo con ella, no explicándosela" (Vargas Llosa, cfr. Cano Gavina, 1972: 93-94).

Y es que más allá de la temática juvenil y la nuclearización primordial de la historia en torno al proceso de integración/desintegración de [un amigo en] un grupo de amigos, más allá del poder mimètico que otorgan a la narración la inmensa mayoría de emplazamientos, ámbitos de actuación y espacios (Valles, 1999) miraflorinos en particular y limeños en general, más allá de la capacidad realista que aportan en el plano verbal los peruanismos, limeñismos y expresiones propias de la jerga juvenil miraflorina y de la época-, a mi entender son específicamente los mecanismos empleados en el ámbito de la voz narrativa los que, primordialmente y de un Modo singular y concreto, construyen esta novela tal y como es (no cualquier 
historia sobre un grupo de jóvenes, sino, este relato, con su qué y su cómo, contando tal historia y de tal preciso modo); y también (los mecanismos narrativos) se integran y coactúan, semióticamente, para configurar, mediante procesos verbosimbólicos, la significación textual y estéticamente para provocar los efectos estilísticos generados: las sensaciones de extrañeza y de distancia/cercanía que aportan los continuos y famosos cambios de persona narrativa (fuera/dentro, ellos/nosotros), propios de un extraño, y no tipificado, caso de narrador bipolar o desdoblado, permanente transeúnte entre lindes, que he optado por denominar transdiegético y que usa para sus fines el autor implícito; una historia grupal que se construye poliédricamente en el relato mediante la alternancia sucesiva e incesante de voces y visiones personales, distintas y fragmentarias; la viveza, el tono juvenil y el carácter de grupo que dan la yuxtaposición acumulativa y niveladora, no organizada ni jerarquizada, no solo de las voces sino de los estilos, palabras y discursos; finalmente, la representación realista de la juventud limeña burguesa de la época (voluntaria y críticamente aislada de otras juventudes, otros barrios y otras realidades limeñas) mediante la penetración novelesca de su sociolecto grupal juvenil, no solo lingüístico o verbal sino estilístico y discursivo.

Entiendo, pues, que son la conjunción y el sincretismo muy especiales de los anteriores factores los que diseñan de un modo principal y definitivo la novela Los cachorros y los que explican no solo el qué sino el cómo y por qué se relata eso y así, objeto exclusivo de este artículo. Son, por tanto, en mi opinión, estos mecanismos coactuantes en la voz narrativa los mayores responsables de que se retrate realísticamente (ciertamente representando pero también - y esto es lo más característico de la literatura - contando significativa y estéticamente de ese modo) ese largo proceso de identificación grupal y progresiva desafección personal hasta la separación del conjunto, que constituye el centro dramático de la historia de una patota de jóvenes burgueses miraflorinos en torno a mil novecientos cincuenta [y algo].

Procederé ahora a examinar, más detenidamente, el funcionamiento concreto de cada uno de estos procedimientos, intentando mirar no tanto hacia su identificación técnica y cuantificación narrativa sino hacia el 
papel semiótico y estético que cumplen para reforzar con el lenguaje y la voz narrativa la ficción realista.

\subsection{El narrador transdiegético}

Si hay algún elemento de la voz que, desde el comienzo del relato e incesantemente hasta su término, causa extrañeza y una consecuente atención reforzada del lector real, es la persona narrativa. La alternancia de la tercera y la primera persona del plural (ellos/nosotros) es ya no solo continua sino abruptamente puesta: permanente y violentamente ubicada en la misma estructura, oración e incluso párrafo, es decir, directamente al lado. Véanse los famosos fragmentos inicial y final de la obra:

Todavía llevaban pantalón corto ese año, aún no fumábamos, entre todos los deportes preferían el fútbol y estábamos aprendiendo a correr olas, a zambullirnos desde el segundo trampolín del Terrazas, y eran traviesos, lampiños, curiosos, muy ágiles, voraces. Ese año, cuando Cuéllar entró al Colegio Champagnat. [...]

Eran hombres hechos y derechos ya y teníamos todos mujer, carro, hijos que estudiaban en el Champagnat, la Inmaculada o el Santa María, y se estaban construyendo una casita para el verano en Ancón, Santa Rosa o las playas del Sur, y comenzábamos a engordar y a tener canas, barriguitas, cuerpos blandos, a usar anteojos para leer, a sentir malestares después de comer y de beber y aparecían ya en sus pieles algunas pequitas, ciertas arruguitas (Vargas Llosa, 1967: 55 y 121).

Estos dos párrafos desempeñan un doble papel en la novela. De una partey temporalmente, con respecto a la duración o velocidad (Genette, 1972; 1991), constituyen rápidos sumarios, resúmenes narrativos que permiten, indirecta y asociativamente, identificar la edad del grupo de los personajes: la juventud en un caso, la madurez en otro. También y paralelamente, funcionan como puertas de la fábula, en cierto modo íncipit y éxplicit, apertura y cierre que enmarcan, en los párrafos inmediatamente posterior 
y anterior, el inicio [llegada de Cuéllar al colegio] y fin [alusión a la muerte de Cuéllar] de la historia narrada, sin merma de representar, asimismo, en su estrategia lectoral hacia un lector implícito, unos recorridos virtuales e intratextuales de lectura proléptico e indagatorio inicial y analéptico y conclusorio final (Prince, 1987: 21; Valles, 2004: 412-413).

Pero, además, tales párrafos operan simbólicamente porque, como adelantaba, reflejan ese juego de oxímoron de personas narrativas (ellos/ nosotros) que continúa durante todo el texto; esa [aparente] dualidad de instancias narrativas violenta y abruptamente opuestas y puestas en cada intervención mínimamente amplia, en cada presencia del discurso directo del narrador, y que llega en ocasiones a anacolutos estilísticos entre el sujeto y predicado tan estridentes como el que sigue:

"Ellos lo estábamos vengando, Cuéllar, en cada recreo pedrada y pedrada contra la jaula de Judas...” (Vargas Llosa, 1967: 67).

La cuestión no solo supone una estilística rotura de la sintaxis lingüística, sino también narratológica, que, a mi entender, va en principio y formalmente más allá de las tradicionales, conocidas y utilizadas posibilidades narrativas, diferenciadas por Genette respecto a la persona narrativa o conexión identitaria narrador/personajes; esto es, la intervención actoral o no del narrador en la historia que él mismo relata (narrador hetero, homo o autodiegético) (Genette, 1972: 252 y ss.). En la medida en que el narrador de Los cachorros se coloca continuamente, como hemos visto, en los dos planos de actuación, tanto dentro como fuera de la acción contada (ellos/nosotros), a la vez como relator-no interviniente y relator-personaje [no principal], no es, aparentemente, ni solo heterodiegético ni solo homodiegético.

Al contrario, en una práctica narrativa bastante novedosa — creo que coherente con todo su proyecto narrativo de la década de los sesenta y muy consciente de la experimentación escritural一, tanto en la dimensión sintáctica (anacolutos y violenta oposición de personas gramaticales narrativas) como en la estilística (extrañeza en el lector y sucesivos efectos casi de zoom de cámara de vídeo: incesantes y alternantes efectos de 
acercamiento/alejamiento con el uso de nosotros/ellos) y simbólica (según Carlos Fuentes - 1969: 43 - los cambios pronominales "se apropian del sistema neutro y ahistórico, lo tiñen, por así decirlo, de presencia individual y colectiva"), pero acaso no tanto en cuanto a su atipicidad narratológica, Vargas Llosa, a juzgar por las marcas pronominales, permanentemente parece mudar al narrador de persona o, mejor dicho, desdoblarlo, darle una doble identidad, otorgarle un estatuto bipolar, traspasar al narrador, en un imposible, el desdoble posible en el personaje (sea este imaginario o "real" dentro del universo ficcional realista o fantástico: transustanciaciones de Drácula en murciélago, transfiguraciones de Jekyll en Hyde -Valles, 2004: 586-587) .

Ahora bien, esto no quiere decir que, en el fondo y realmente, haya una doble persona o identidad narrativa o un mismo narrador hetero y homodiegético a la vez, algo ortológicamente imposible; hay más bien, un juego narrativo y una licencia literaria que, para provocar los efectos antes descritos, permiten falsos aunque continuos deslizamientos desde la hererodiégesis a la homodiégesis (del ellos al nosotros), lanzan y promueven la imagen de un [falaz] doble narrativo del narrador heterodiegético, caracterizado [falazmente] como homodiegético. El narrador, no siendo interviniente en la historia que relata pero en coherencia con su perspectiva omnisciente (Genette, 1972: 183-224), a veces puramente narrativa y a veces multiselectiva (Friedman, 1955: 1160-1184), y, sobre todo y como plantearé después, con un enlace más que evidente a la imagen intratextual del autor implícito no representado textualmente (Booth, 1961: 70-71; Villanueva, 1989: 185; Valles, 2008: 234), a causa de su patente y continuada identificación memorialística con los personajes escolares del relato [recuerdos de hechos, costumbres y gustos juveniles similares o incluso idénticos, como el episodio del perro: yo también fui así e hice/me ocurrió $\mathrm{eso}^{3}$ ], se desplaza permanentemente hacia la misma para introducirse como otro actor más: la impostura es evidente al no formar parte del conjunto de los jóvenes, identificados y nominados, del grupo.

$3 \quad$ Me refiero al episodio sufrido por el autor de niño en Cochabamba con el gran danés del señor Beckmann que le destrozó el fundillo del pantalón (Vargas Llosa, 1993: 24). 
No obstante, las marcas formales, sintácticas y narrativas, y sus dimensiones significativas y efectos estilísticos, hablan de un narrador que atraviesa las fronteras de la intervención actoral, para ir desde la heterodiégesis a la homodiégesis, retornar y volver de nuevo permanente e incesantemente. Considero por ello apropiado hablar en esta novela de Vargas Llosa de narrador transdiegético para referirme a aquel que, siendo en el fondo un alter ego del narrador heterodiegético lanzado por motivos de identificación sentimental y memorial autoral al campo de la actuación como [falaz] imagen homodiegética, no obstante se muestra discursiva y narrativamente como un narrador permanentemente movedizo, un transeúnte continuo entre fronteras, un narrador-barquero que se traslada sin cesar del uno al otro margen del río de su no participación/ participación actoral, del ellos al nosotros.

Pero la transdiégesis tiene también otra importante motivación. En esa segunda voz supuestamente actoral y homodiegética del narrador heterodiegético desdoblado reside, de forma latente y oculta, el discurso y la imagen del autor implícito (Booth, 1961: 70-71) o intratextual no representado, una instancia intranarrativa no directamente presentada ni representada del autor — que se halla, al igual que el narrador con su narratario en este caso general, latente y tampoco identificado, en lógico correlato con el lector implícito o estrategia de lectura intratextualmente requerida - . Aparece así lo que García Landa (1996) llama "autor- narrador"4 en esa voz en primera persona del plural: en ella se deposita, de un lado, el tono memorialístico y evocativo del relato, y en otro, se deja constancia de la identificación personal con ciertos acontecimientos y actuaciones de los personajes; ambas cuestiones son las dos principales huellas textuales dejadas por el autor implícito no representado. A través de estas operaciones del autor implícito, efectuadas mediante esa segunda voz de la imagen desdoblada del narrador, se crea la función testimonial [yo estaba allí, a mí también me ocurrió eso] que genera una imagen verídictoria.

$4 \quad$ Se trata en el fondo de la variante menos palpable pero presente de la clásica fórmula de la para parábasis o intrusión autoral.

Bol. Acad. peru. leng. 50(50), 2010 
Así pues, más allá de la novedad técnica de la transdiégesis, que ya resulta interesante para cualquier teórico y estudioso de la literatura, lo importante es cómo el recurso se emplea dentro de la novela para generar significación y efectos estéticos coherentes con la pretensión realista: en una primera instancia, con la alternancia abrupta y continua de personas gramaticales, al lector implícito (Iser, 1976: 59-64 y 70-87) se le ofrece, como una dimensión experimental y lúdica, una historia a través de unas [supuestas] identidades narrativas cambiantes, que coinciden estilísticamente con una especie de permanentes efectos de zoom que acercan y alejan sucesivamente la imagen representada $;{ }^{5}$ en segundo término y sobre todo, al segregar con el "nosotros" la imagen del narrador-actor, el autor implícito aporta su identificación y su tono memorialístico al relato para propiciar una función de testificación que genera efectos de autentificación y de consecuente veridicción: la historia se hace así verosímil, se muestra semánticamente realista y epistémicamente creíble.

\subsection{La construcción poliédrica: polifonía coral, visión caleidoscópica}

Si la alternancia ellos/nosotros provoca ese efecto de zoom incesante, el conjunto de voces y visiones en el texto, también permanente y desigualmente diseminado y a veces sin identificación, clara o implícita, del sujeto discursivo o perspectivístico, aporta una representación fragmentaria, poliédrica y relativista de la historia, coherente con su carácter esencialmente grupal, coaptando la plurifonía no totalmente orquestada, estructurada y jerarquizada, tendente a la coralidad, con la suma caleidóscopica de visiones que permite la omnisciencia multiselectiva antes mencionada.

Efectivamente, la historia de integración/desintegración de Cuéllar [en] y su grupo se muestra en una imagen múltiple y fragmentaria, plural y multiplicada, diversa y en ocasiones contradictoria, a veces despersonalizada o colectiva, plurirreflejada por las diversas visiones y

5 Coincide en cierto modo con esta impresión Fernández Ariza (1998: 21-22) al señalar que "debido a la situación que ocupa, el narrador se desplaza por el relato, se identifica con uno u otro personaje, con el grupo inclusive, o bien se distancia de ellos". 
voces que pretenden contarla y/o intervienen y ven la misma. Obsérvese el siguiente fragmento:

(...) hombre, no te vayas todavía, vamos al 'Terrazas', le pedirían la pelota al Chino, ¿no quería jugar por la selección de la clase?, hermano, para eso había que entrenarse un poco, ven vamos anda, solo hasta las seis, un partido de fulbito en el 'Terrazas', Cuéllar. No podía, su papá no lo dejaba, tenía que hacer las tareas. Lo acompañaban hasta su casa, ¿cómo iba a entrar en el equipo de la clase si no se entrenaba?, y por fin acabábamos yéndonos al 'Terrazas' solos. Buena gente pero muy chancón, decía Choto, por los estudios descuida el deporte, y Lalo no era culpa suya, su viejo debía ser un fregado, y Chingolo claro, él se moría por venir con ellos y Mañuco iba a estar bien difícil que entrara al equipo... (Vargas Llosa, 1967: 62).

Al margen de la rapidez y viveza, concordante con el carácter de un grupo de jóvenes, que aporta la elisión de los verbos de lengua y pensamiento, así como de la eliminación de las rayas/dos puntos marcadoras del diálogo/estilo directo o de los nexos introductorios del estilo indirecto, se mezclan en el párrafo citado la voz del propio narrador, su propio discurso y el discurso de los personajes, siempre semiindependizados en el estilo indirecto libre, pero a veces bien en voz colectiva, bien de personaje no identificado, como al principio del fragmento, o en ocasiones con expresión del personaje indirectamente hablante, como al final. De este modo, la historia aparece, incluso, mediada por el filtro de la palabra y perspectiva del narrador, como una imagen permanentemente variable y diversa que se compone e integra mediante las distintas voces y visiones, discursos y perspectivas, de autor implícito, narrador y personajes.

Así pues, de una parte referida a la focalización, la historia se ve como la imagen fragmentada y cambiante, poliédrica y coloreada, integrada y desintegrada, por los cristales del caleidoscopio: la técnica de la representación caleidoscópica (Baquero, 1970: 219-234), consiste fundamentalmente en proyectar una imagen multifocal y diversa del 
objeto narrativo que, en este caso, asociada a la perspectiva omnisciente (Genette, 1972: 183-224; 1991: 30-36) propia del relator heterodiegético en este relato, supone el uso y alternancia de la omnisciencia autoral (con presencia del autor implícito), con la puramente neutral (solo visión no marcada del narrador) y sobre todo con la omnisciencia múltiple selectiva (cambiante y vinculada a distintas visiones de los diversos personajes) (Friedman, 1955: 1160-1184). Disiento en este punto de la idea de Forgues (2009: 90): de que alternen en el relato todos los tipos de visión ("por detrás", "con" y "por dentro", según la muy tradicional tipología de Pouillon replanteada por Todorov en 1966), y más, de que eso pueda determinar la alternancia de los pronombres personales sujetos: de lo último, porque un tema corresponde a la visión y otro a la persona de la voz narrativa [modo/voz, Genette, 1972], aunque tengan su relación e incluso correlación; de lo primero porque, como acabo de indicar, es la perspectiva omnisciente, mutando desde la autoral a la neutral o a la multiselectiva en diversas ocasiones, la que permite el grado de suprasciencia narrativa para identificarse con los distintos personajes conociendo hasta sus sentimientos y pensamientos más íntimos.

En cambio, de otro lado, las diferentes voces y palabras de los diversos personajes - nunca de los distintos discursos, pues no hay un verdadero "dialogismo" en un relato donde las opiniones de los jóvenes personajes del grupo son bastante similares y despersonalizadas - también aportan una representación fragmentaria, poliédrica y relativista de la historia, pero desde una perspectiva verbal que fusiona y nivela plurifónicamente una serie de voces de personajes, tendentes a la coralidad en coherencia con el centro temático grupal juvenil de la historia, pero que no están, pese a la tutela narrativa, demasiado bien orquestadas, definidas y jerarquizadas. Se trata, pues, más de una dimensión polifónica que dialógica en sentido bajtiniano, de una multiplicidad, no demasiado autónoma, ni opuesta, ni en ocasiones siquiera demasiado individualizada y diferenciada, de voces y palabras, y no tanto de una "pluralidad de voces y conciencias independientes e inconfundibles, la auténtica polifonía de voces autónomas" (Bajtín, 1929: 16-179). 
2.3. La yuxtaposición y nivelación de discursos, palabras y estilos

Muy en consonancia con lo anterior se halla la organización discursiva de la novela. De entrada, la configuración tanto gráfica como narrativa es distinta a la usual: no hay diversos párrafos donde se diferencian el discurso de narrador y los discursos autónomos de personajes, aun cuando existan estos en el relato; tan solo se mantiene la lógica del punto y aparte y el cambio de sentido para abrir un nuevo párrafo. Por tanto, la tutela del narrador se extiende por toda la unidad gráfica y de sentido del párrafo, y cubre no ya su propio discurso (bien como sumario diegético o menos diegético), sino, asimismo y siempre, el discurso de los personajes, se produzca este en su dimensión más autónoma de los discursos directos (libre o citado) o de los más dependientes y usuales de la rección del narrador en los discursos indirectos (conceptual, mimético y libre) (McHale, 1978: 249-287):

Pichula Cuéllar volvió a las andadas. Qué bárbaro, decía Lalo, ¿corrió olas en Semana Santa? Y Chingolo: olas no, oloñes de cinco metros, hermano, así de grandes, de diez metros. Y Choto: hacían un ruido bestial, llegaban hasta las carpas, y Chabuca más, hasta el malecón, salpicaban los autos de la pista y, claro, nadie se bañaba. ¿Lo había hecho para que lo viera Teresita Arrarte?, sí, ¿para dejarlo mal al enamorado?, sí. Por supuesto, como diciéndole Tere fíjate a lo que me atrevo y Cachito a nada (...)

¿Por qué se pondría el mar tan bravo en Semana Santa?, decía Fina, y la China de cólera porque los judíos mataron a Cristo, y Choto ¿los judíos lo habían matado?, él creía que los romanos, qué sonso. Estábamos sentados en el malecón, Fina, en ropa de baño, Choto, las piernas al aire, Mañuco, los olones reventaban, la China, y venían y nos mojaban los pies, Chabuca, qué fría estaba, Pusy, y qué sucia, Chingolo, el agua negra y la espuma café, Teresita, llena de yerbas y malaguas, y Cachito Arnilla, y en eso pst pst, fíjense, ahí venía Cuéllar. ¿Se acercaría, Teresita?, ¿se haría el que no te veía? Cuadró el Ford frente al Club de Jazz... (Vargas Llosa, 1967: 107-108). 
En estos fragmentos no solo se aprecian todas las posibilidades de las tres grandes modalidades discursivas (de narrador y de personaje, ya directo ya indirecto) sino que se evidencia la yuxtaposición y nivelación tanto de los mismos como incluso de los fragmentos puramente dialógicos y de los sumarios puramente narrativos. Se reincide, pues, en cierta medida como continuación de la alternancia ellos/nosotros, en la lógica de la aposición violenta, directa y abrupta de elementos contrapuestos, magnificada por la elisión de nexos, verbos de lengua, espacios, renglones, rayas y otras marcas de estilos, pero, además, en este caso, con el añadido de hacerlo con discursos y estructuras (narración/diálogo/descripción, palabras y pensamientos, oraciones independientes, etc.) pertenecientes a órdenes y jerarquías distintas.

De este modo, se refuerza semiótica y estilísticamente el núcleo de sentido de la historia narrativa: las elisiones y yuxtaposiciones promueven la viveza y rapidez del ritmo narrativo en coherencia con la fuerza y dinamismo juveniles; las igualaciones y nivelaciones de elementos pertenecientes a órdenes jerárquicos diversos confirman el sentido unitario y gregario del grupo, predominante - todavía - sobre las actitudes y posiciones individuales de sus miembros.

Precisamente Roberto Bolaño veía, además de la musicalidad que enlaza con el habla oral y viva a que ahora nos referiremos, la velocidad como la otra gran característica de esta novela:

He hablado antes de la velocidad que tienen Los cachorros y sus tres hermanas gemelas. No hablé de su musicalidad, una musicalidad sustentada en el habla cotidiana, en las voces que puntúan el relato, y que se imbrica con la velocidad del texto. Velocidad y musicalidad son dos constantes en Los cachorros y de alguna manera este ejercicio magistral sobre la velocidad y la musicalidad le sirve a Vargas Llosa de ensayo para la que poco después sería una de sus grandes novelas y una de las mejores escritas en español del siglo XX: Conversación en La Catedral (Bolaño, 11-8-1999). 


\subsection{El sociolecto de la juventud miraflorina de la época}

Hay un cuarto y último elemento de la voz narrativa que coactúa fundamentalmente, aparte del carácter verosímil que aportan la propia historia, las posiciones reafirmativas del autor implícito y del narrador y las localizaciones espaciales - miraflorinas, limeñas — , para generar la credibilidad lectoral y el efecto realista de la novela.

Ciertamente, la novela introduce de modo particularmente acertado el habla de los jóvenes miraflorinos del momento, es decir, materializa textual y narrativamente un discurso social, transdiscursiviza y transcodifica el sociolecto (Zima, 1982) de la juventud limeña de la época. Julio Ortega comenta el carácter de crónica oral del relato que introduce

"un habla de melosa melodía dirigida desde y a chicos mimados, creándose así esa propiedad musical, esa unidad de habla, irónica y piadosa a la vez" (Ortega, 1971: 270).

Y es precisamente la presencia novelesca de tal discurso grupal sociohistórico, de tal sociolecto, la que provoca el efecto de un habla oral, viva y coloquial de una parte, grupal y colectiva de otra, que tiende a reforzar el carácter realista de la obra. Obsérvese el siguiente fragmento:

Nos parábamos en la esquina y fíjate, ahí estaban los ómnibus, eran las de Tercero, y la de la segunda ventana es la hermana del cholo Cánepa, chau, chau, y ésa, mira, háganle adiós, se rió, se rió, y la chiquita nos contestó, adiós, adiós, pero esa no era para ti, mocosa, y ésa, y ésa. A veces les llevábamos papelitos escritos y se los lanzaban a la volada, qué bonita eres, me gustan tus trenzas, el uniforme te queda mejor que a ninguna, tu amigo Lalo, cuidado, hombre, ya te vio la monja, las va a castigar, ¿cómo te llamas?, yo Mañuco, ¿vamos el domingo al cine?, que le contestara mañana con un papelito igual o haciéndome a la pasada del ómnibus con la cabeza que sí. Y tú Cuéllar, no le gustaba ninguna, si, esa que se sienta atrás, ¿la cuatrojos?, no, no, la de al ladito, por qué no le escribía entonces, y él qué le ponía, a ver, a ver, ¿quieres ser mi 
amiga?, no, qué bobada, quería ser su amigo y le mandaba un beso, sí, eso estaba mejor, pero era corto, algo más conchudo, quiero ser tu amigo y le mandaba un beso y te adoro, ella sería la vaca y yo seré el toro, ja ja. (Vargas Llosa, 1967: 75-76).

Se aprecia aquí, como en casi toda la obra en realidad y como antes avanzaba, el doble carácter del lenguaje juvenil presente en Los cachorros: oral, vivo y coloquial; grupal y colectivo.

¿Por qué tal habla es oral, viva y coloquial? Primeramente porque está cargada de estructuras y expresiones propias del lenguaje oral y cotidiano, a lo que contribuyen muy notablemente la abundancia de peruanismos y localismos limeños de un lado y de términos propios de la jerga juvenil y estudiantil ("chanconcito", "chupete", "cocacho", "caerle a", "cuatrojos", etc.) de otro; también provocan ese efecto, sobre todo en los 3 primeros capítulos del relato [que ocupan no obstante las tres cuartas partes de la obra] la variada y numerosa presencia de onomatopeyas, que son particularmente empleadas en el habla infantil y juvenil y que van desapareciendo conforme avanza la narración y crecen en edad los personajes (Frank, 1973-1974: 574). En segundo término, porque el narrador acentúa ese carácter fundamentalmente mediante tres operaciones narrativas y estilísticas: la elisión de verbos o de pensamientos y de nexos; la cesión directa de la palabra de uno a otro personaje en rapidísimos y no marcados procesos de embrague y desembrague internos (GreimasCourtés, 1979: 73), de ida y vuelta de la palabra del narrador a los personajes; la eliminación casi absoluta de signos de puntuación y marcas formales del diálogo y el intercambio y alternancia de palabras entre los personajes.

¿Y por qué es, asimismo, un lenguaje de carácter grupal y colectivo, sociolectal? Porque, si bien con la transposición impuesta por los códigos literarios del texto, lo que se transdiscursiviza es una forma de habla y expresión, viva y coloquial desde luego, de un grupo social concreto y de unos años concretos: de la juventud burguesa limeña de los años cincuenta. En cierto modo, Vargas Llosa opta aquí por concentrar y reducir a un 
sector sociogeneracional el discurso sobre Lima criolla ${ }^{6}$ (Ortega, 1997: 58-60), propio de casi todas sus novelas.

\section{Conclusiones}

En su artículo sobre la concesión del reciente y merecidísimo Nóbel a Vargas Llosa, Muñoz Molina escribía:

(...) en Vargas Llosa los artificios de la novela están calculados con plena intención, como elementos de un organismo dinámico que depende de la eficacia de cada uno de ellos para que la historia se vaya desplegando en la conciencia del lector. Cuanto mejor es una novela más activamente está implicado en ella el proceso de lectura, desde luego, pero en el caso de las de Vargas Llosa ese acto de leer es central: el modo en que la información se va administrando configura las expectativas sobre la naturaleza y la forma de la historia que se tiene por delante, o que se va extendiendo alrededor de uno. Las voces narrativas, las indicaciones de lugar, los fragmentos de conversaciones, los puntos de vista, configuran un murmullo que solo se podrá dilucidar con la debida atención, en estado de alerta, con el oído dispuesto a detectar resonancias que nos permitan intuir las formas más amplias de la melodía. (Muñoz Molina, 8/10/2010).

Ciertamente, la obra del autor peruano enfatiza la dimensión de la necesaria cooperación interpretativa lectoral que cualquier novela reclama intratextualmente, con mayor o menor énfasis. Pero también utiliza magistralmente, como yo había dicho antes y Muñoz Molina cita

$6 \quad$ Ejemplificando su uso en distintos relatos y modalidades narrativas, entre ellas en la novelística de Vargas Llosa, que incluye en el discurso de Lima criolla, julio Ortega, en El principio radical de lo nuevo, ha tipificado los distintos discursos que se entrecruzan y oponen dialógicamente para constituir de modo distinto y contrario, aunque coexistente — básicamente como sociolectos y/o idiolectos-, la capital peruana: los discursos de Lima como centro, como centro vacío, de Lima criolla, de la cultura popular, el discurso especializado y el discurso literario. 
al final, las voces narrativas, las indicaciones de lugar, los fragmentos de conversaciones.

En este artículo, dejando de lado otras cuestiones también muy sugerentes que se concitan en Los cachorros, he querido demostrar justamente cómo la voz narrativa adquiere un papel primordial para crear la dimensión realista de la obra: un narrador transdiegético, incesante, transeúnte entre los lindes de la hetero y homodiégesis, que incorpora a la segunda de sus voces (ellos/nosotros) la presencia latente del autor intratextual o implícito para ir, desde la falaz participación coactoral, la memoria y la afinidad sentimental, hacia la sanción como ciertos de los acontecimientos verosímiles de la historia; una imagen de la realidad presentada fragmentaria y relativistamente, desde la polifonía y la visión caleidóscopica, pero coherente con el carácter pluriindividual y grupal del argumento y de la narración; un lenguaje que suprime y yuxtapone palabras, sintagmas y oraciones y que a la vez nivela frases y discursos, generando la identificación estética de lo representante y lo representado: la rapidez narrativa con la viveza juvenil, la igualación discursiva con el carácter gregario de las pandillas; finalmente, la reproducción realista del sociolecto juvenil miraflorino en una doble forma: oral, viva y coloquial, grupal y colectiva.

Compaginando estos cuatro procedimientos de la voz narrativa, Vargas Llosa logra, a mi entender, hacer corresponder, en un altísimo grado, el relato con la representación realista del mundo en la historia novelesca, armonizar la forma con el contenido, fundir estilísticamente el signo con su denotatum: un ejercicio literario solo reservado para las [pequeñas] grandes novelas. 


\section{BIBLIOGRAFIA}

ALEGRÍA, A. (2001). "Vargas Llosa cambia de género". En AA.W, Las guerras de este mundo. Sociedad, poder y ficción en la obra de Mario Vargas Llosa, Lima, Planeta Perú, 2008, pp. 209'214.

ARMAS MARCELO, J.J. (2001). "Jekyll y Hyde, las dos escrituras". En AA.VV., Las guerras de este mundo. Sociedad, poder y ficción en la obra de Mario Vargas Llosa, Lima, Planeta Perú, 2008, pp. 57'73.

BAJTín, M. (1929). Problemas de la poética de Dostö̈evski. México D.F., Fondo de Cultura Económica, 1986.

BAQUERO GOYANES, M. (1970). Estructuras de la novela actual. Madrid, Castalia, 1989.

BOLANO, R. (1999). “De la diferencia a la dignidad". El mundo, 11-8- 1999.

BOOTH, W.C. (1961). La retórica de la ficción. Barcelona, Bosch, 1974.

CANO GAVIRIA, R. (1972). El buitre y el ave fénix, conversaciones con Mario Vargas Llosa. Barcelona, Anagrama.

FERNÁNDEZ ARIZA, G. (1998). "Introducción”. VARGAS LLOSA, M, Los cachorros. Madrid, Cátedra, pp. 11-50.

FERNÁNDEZ CARMONA, J.C. (2007). El mentiroso y el escribidor. Teoría y práctica literarias de Mario Vargas Llosa. Lima, Fondo Editorial del Pedagógico San Marcos.

FORGUES, R. (2009). Mario Vargas Llosa: ética > creación. Lima, Universidad Ricardo Palma (cap. III, "Los cachorros", pp. 69-92). 
FRANK, R.M. (1973-1974). "El estilo de Los cachorros". Anales de Literatura Hispanoamericana, 2-3, 1973-1974.

FRIEDMAN, N. (1955). "Point oí View in Fiction: Development of a Critical Concept”. PMLA, 70, pp. 1160-1184.

FUENTES, C. (1969). La nueva novela hispanoamericana. México D.F., Joaquín Mortiz.

GARCÍA LANDA, J.A. (1996). "Nivel narrativo, status, persona y tipología de las narraciones". Miscelánea: A Journal of English and American Studies, 17, 1996, pp. 91-121.

GENETTE, G. (1972). Figures, III. París, Seuil.

. (1991). Ficción Y dicción. Barcelona, Lumen, 1993.

GREIMAS, A.J. y COURTÉS, J. (1979). Semiótica. Diccionario razonado de la teoría del lenguaje, II. Madrid, Gredos, 1991.

ISER, W. (1976). El acto de leer. Teoría del efecto estético. Madrid, Taurus, 1987.

McHALE, B. (1978). "Free Indirect Discourse: A Survey of Recent Accounts", PTL, 3, pp. 249-287.

MUÑOZ MOLINA, A. (2010). "El lector en el laberinto". El País, 8-10- 2010.

ORTEGA, J. (1971). "Sobre Los cachorros". Homenaje a Mario Vargas Llosa. Madrid, 1971.

. (1997). El principio radical de lo nuevo. Postmodernidad, identidad y novela en América Latina. Lima, Fondo de Cultura Económica, 
OVIEDO, J.M. (2007). Dossíer Vargas Llosa. Lima, Taurus,

. y VARGAS LLOSA, M. (2001), "La literatura, la vida y el poder en la obra de Vargas Llosa. Diálogo entre Mario Vargas Llosa y José Miguel Oviedo". En AA.VV, Las güeñas de este mundo. Sociedad, poder y ficción en la obra de Mario Vargas Llosa, Lima, Planeta Perú, 2008, pp. 211- 251.

PRINCE, G. (1987). A Dictionary of Narratology. Lincoln \&. London, The University of Nebraska Press.

VALLES CALATRAVA, J. (1999). El espacio en la novela. Organización uy funcionamiento del espacio en La ciudad de los prodigios de Eduardo Mendoza. Almería, Universidad de Almería.

. (2004) (dir.) Diccionario de Teoría de la Narrativa. Granada, Alhulia.

. (2008). Teoría de la narrativa. Una perspectiva sistemática.

Madrid-Frankfurt, Iberoamericana-Vervuert.

VARGAS LLOSA, M. 1967). Los cachorros (ed. G. FERNÁNDEZ ARIZA). Madrid, Cátedra, 1998. . (1993). El pez en el agua. Madrid, Alfaguara, 2005.

VILLANUEVA, D. (1989). El comentario de textos narrativos: la novela. Gijón, Júcar, 1992.

ZIMA, P.V. (1982). L'indifférence romanesque. Sartre, Moravia, Camus. París, Le Sycomore.

\section{Correspondencia:}

\section{José R. Valles Calatrava}

Catedrático de Teoría de la Literatura de la Universidad de Almería.

Correo electrónico: jrvallesc@mtin.es 